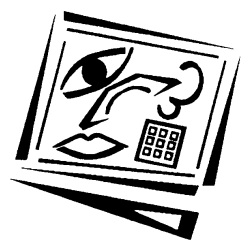

\title{
Factors influencing vocational teacher's use of online functionalities in Australia
}

\author{
Ian Robertson \\ RMIT University
}

\begin{abstract}
Robertson (2006b) surveyed Australian vocational teachers to propose that the criteria of newness, complexity, compatibility and locus of control are influential in shaping the frequency of online functionality use. The current paper tests and further refines this proposition by comparing the likelihood that online functionalities will be used at least monthly by vocational teachers whose delivery approaches are primarily face to face and non-face to face. Generally, it is found that the longer an online functionality has been available for use in vocational education, the greater the likelihood of regular use in face to face and non-face to face delivery approaches. However, the increase of regular use over time is not universal. A complex relationship between the functionality's newness, complexity, and compatibility is influential in shaping the likelihood of regular use. Whereas compatibility relates to a teacher's existing practices and needs, locus of control is specifically concerned with a teacher's pedagogic preferences. It is suggested that vocational teachers are more likely to regularly use functionalities that promote teacher control rather than learner control. The implications of the proposed relationship between the four criteria and the likelihood that online functionalities will be used by vocational teachers are discussed, and opportunities for further research identified.
\end{abstract}

\section{Introduction}

In Australia, the vocational education and training (VET) system incorporates training organisations that are registered to deliver accredited vocational programs. These include public Technical and Further Education (TAFE) providers, private providers, adult and community education providers, and registered organisations in some universities, schools and commercial enterprises. With a focus on sustainability, the Australian VET system aims to increase the uptake of e-learning and to be recognised as a global leader in applying new technologies to vocational education and training products and services (Australian National Training Authority, 2000; Department of Education Science and Training, 2005). In order to achieve these aims, the use of technology will need to be systemically 
embedded into the teaching practices of vocational practitioners. In the words of other researchers, "as more colleges and universities seek to use instructional technology, administrators must have a framework for effectively integrating technology" (Surry, Ensminger \& Jones, 2003, p.3). This paper contributes to the adoption of technology through a greater understanding of factors that influence why some technologies are adopted and used more frequently by teachers.

Whether a person decides to adopt a technology and how frequently they use the technology are different concepts. Adoption is a precursor to frequency of use. Rogers (1995) and Surry, Ensminger and Haag (2005) provide some explanation of the adoption process, but there is a paucity of literature that engages in a consideration of the factors that shape how frequently technologies are used. In Australia, Department of Education, Science and Training funded projects have reported vocational teachers use of online functionalities (I \& J Management Services, 2005, 2006). Whilst these reports provide national data, use of online functionalities is based upon an at least single use in a single year. No attempt is made to identify the frequency of use or the factors that might be influential.

Here, the term 'online functionalities' is used in preference to more commonly used terms such as online learning and e-learning. Online functionality implies the deconstruction of the more generic terms of online and e-learning into functional elements. When used in an analysis of the frequency with which practitioners use the component elements of online technologies for teaching, this approach provides a more refined analysis by revealing which functionalities are used more or less frequently (Robertson, 2006a).

By comparing the use of 21 online functionalities by 138 Australian vocational teachers, Robertson (2006b) proposed that the characteristics of newness, complexity, compatibility and locus of control are influential in shaping the frequency with which vocational teachers use specific online functionalities. This paper tests and refines that proposition. The vocational practitioners were drawn from the Australian Flexible Learning Framework's 2005 Networks Community Forum. This forum comprises over 500 participants with a common interest in flexible learning and the use of technology.

The 21 functionalities surveyed relate to content distribution, synchronous and asynchronous communication, searches for information and automated assessment. These were "derived from personal experience, identifying those functionalities that are known to be used by vocational practitioners or functionalities that are promoted for use through the Australian Flexible Learning Framework" (Robertson, 2006b, p.40). Respondents were able to 
indicate that they used each online functionality daily, weekly, monthly or less than monthly. They were also able to indicate that they were unsure. As would be expected, the frequency of use of the 21 online functionalities was variable amongst the respondent group.

This paper revisits key data reported by Robertson (2006b). The frequency of use of online functionalities reported by those teachers who described their primary teaching mode as face to face is compared with those who described their primary teaching mode as non-face to face. The results of this comparison are used to test the usefulness of the criteria of newness, complexity, compatibility and locus of control in explaining differences in frequency of use of online functionalities between the two groups of respondents. The justification for this comparison is based on the premise that the means through which the face to face and non-face to face teachers distribute learning materials and the means through which teachers and learners communicate are fundamentally different.

\section{Demographics of the survey group}

Robertson (2006b) collected data relating to respondents' primary mode of teaching and other demographic data. Respondents were able to identify their modes of delivery as:

- Primarily face to face.

- Primarily face to face with some non-face to face.

- Face to face and non-face to face in roughly equal proportions.

- Primarily non-face to face with some face to face.

- Primarily non-face to face i.e. minimal scheduled face to face.

Here, those respondents who indicated that their delivery approach was primarily face to face $(n=50)$ and primarily face to face with some non-face to face $(n=19)$ are combined as a group whose primary delivery strategy is face to face $(n=69)$. Those who indicated that their delivery approach was primarily non-face to face $(n=9)$ and primarily non-face to face with some face to face $(n=16)$ are combined into a group whose primary delivery strategy is non-face to face $(n=25)$. The remaining respondents reported that their primary delivery approach was face to face and non-face to face in roughly equal proportions $(n=15)$. Their data are excluded from the current analysis on the basis that it is unclear if these respondents deliver by a combination of face to face and non-face to face in a single program or face to face in some programs and non-face to face in others.

Demographic data for gender, age, teaching time fraction, years of teaching experience, geographic location and self declared level of skill using technology are summarised in Table 1. When the respondent groups of face 
to face and non-face to face teachers are considered collectively, the total respondent group shows similarity with the results of a national survey of TAFE teachers (NCVER, 2004). There is a roughly equal split according to gender, there are more part time than full time staff, few staff are less than 30 years old, and between two-thirds and three-quarters of TAFE teachers are older than 40 years with a relatively even split between $40-49$ year olds and $50+$ year olds. More than 40\% have been employed in TAFE for more than 15 years (NCVER, 2004).

Table 1: Demographic data for respondent groups

\begin{tabular}{|c|c|c|c|c|c|}
\hline \multirow{2}{*}{\multicolumn{2}{|c|}{ Data }} & \multicolumn{2}{|c|}{ Face to face teachers } & \multicolumn{2}{|c|}{ Non face to face teachers } \\
\hline & & Number & $\%$ & Number & $\%$ \\
\hline \multirow[t]{2}{*}{ Gender } & Male & 41 & 59.4 & 16 & 64.0 \\
\hline & Female & 28 & 40.6 & 9 & 36.0 \\
\hline \multirow[t]{4}{*}{ Age } & 20-29 years & 3 & 4.4 & 1 & 4.0 \\
\hline & $30-39$ years & 13 & 18.8 & 2 & 8.0 \\
\hline & 40-49 years & 25 & 36.2 & 12 & 48.0 \\
\hline & $50+$ years & 28 & 40.6 & 10 & 40.0 \\
\hline \multirow[t]{5}{*}{ Time fraction } & 1 day/week & 9 & 13.2 & 9 & 39.1 \\
\hline & 2 days/week & 11 & 16.2 & 2 & 8.7 \\
\hline & 3 days / week & 7 & 10.3 & 1 & 4.4 \\
\hline & 4 days/week & 6 & 8.8 & 3 & 13.0 \\
\hline & 5 days/week & 35 & 51.5 & 8 & 34.8 \\
\hline \multirow{4}{*}{$\begin{array}{l}\text { Years of } \\
\text { teaching } \\
\text { experience }\end{array}$} & $0-4$ years & 13 & 18.9 & 1 & 4.2 \\
\hline & 5-9 years & 23 & 33.3 & 5 & 20.8 \\
\hline & $10-14$ years & 12 & 17.4 & 2 & 8.3 \\
\hline & $15+$ years & 21 & 30.4 & 16 & 66.7 \\
\hline \multirow[t]{3}{*}{ Location } & Metropolitan & 58 & 84.0 & 10 & 40.0 \\
\hline & Regional & 10 & 14.5 & 11 & 44.0 \\
\hline & Remote & 1 & 1.5 & 4 & 16.0 \\
\hline \multirow{4}{*}{$\begin{array}{l}\text { Experience } \\
\text { with } \\
\text { technology }\end{array}$} & Beginner & 4 & 5.8 & 0 & 0.0 \\
\hline & Intermediate & 28 & 40.6 & 5 & 20.0 \\
\hline & Experienced & 22 & 31.9 & 4 & 16.0 \\
\hline & Advanced & 15 & 21.7 & 16 & 64.0 \\
\hline
\end{tabular}

The demographics of face to face and non-face to face respondent groups vary in some respects. Face to face teachers are more likely to: be employed full time $(51.5 \%)$ than their non-face to face counterparts (34.8\%); have less than 10 years teaching experience $(52.2 \%)$ than non-face to face teachers $(25.0 \%)$; be employed in a metropolitan area $(84.0 \%)$ than non-face to face teachers (40\%); and to describe their level of expertise with technology as beginner or intermediate $(46.2 \%)$ than non-face to face teachers $(20.0 \%)$. Therefore, non-face to face respondents are more likely to be employed part time, have more than 10 years teaching experience, be located in either regional or remote locations and describe themselves as expert in the use of technology than their face to face colleagues. 
Less than $6.0 \%$ of face to face respondents and $0.0 \%$ of non-face to face respondents declared themselves as having a beginner level of expertise with respect to using technology. Some might think that this level is lower than might be expected. Given that the respondents are participants in a community forum with a common interest in flexible learning and the use of technology, it is possible that the respondent group has a greater level of technical skill than the general population.

\section{Comparison of online functionality use across sub-groups}

The calculation of at least monthly use of a functionality is applied as the point of comparison for the analysis of the usefulness of the criteria of newness, complexity, compatibility and locus of control in shaping the likelihood that an online functionality will be used by a group of vocational teachers. Through the addition of those respondents who indicated that they used an online functionality daily, plus those who indicated that they used the functionality weekly, plus those who indicated that they used the functionality monthly, the total number of all individuals using the functionality at least monthly is identified. Table 2 summarises the cumulative (at least) monthly usages for each of the 21 functionalities for the face to face and non-face to face groups, and, the differential between the two groups. General observation of the results shows that:

- The likelihood that practitioners will use specific online functionalities at least monthly ranges from zero to $95 \%$ for the non-face to face group and zero to $83.3 \%$ for the face to face group.

- There is no example where the likelihood that the face to face group will use an online functionality at least monthly is greater than for the nonface to face group.

- The difference between the likelihood that the non-face to face and face to face groups will use a specific functionality at least monthly is variable. For example, the difference is less than $10.0 \%$ in the cases of the use of video conference software $(0.0 \%)$, searches for learners to access information $(2.4 \%)$ and the use of the Internet/intranet for simulations and scenario based learning $(5.3 \%)$. The difference is almost $50 \%$ in the cases of group email between the teacher to learners $(48.1 \%)$ and the use of virtual classroom software $(49.6 \%)$.

\section{Evaluating the usefulness of criteria affecting the frequency of use of online functionalities}

Diffusion of innovations (Rogers, 1995) is a general theory of innovation adoption derived from a range of traditions including sociology, health, communications, and economics. Rogers describes five factors that influence the likelihood that an innovation will be adopted: relative advantage; 
compatibility; trialability; observability; and complexity. Relative advantage relates to the perceived benefit that will accrue as a result of adoption in comparison to existing practices. Compatibility refers to the perceived level of congruence between the innovation, existing values, past experiences and existing needs. Trialability refers to the degree to which experimentation is possible, and observability to the degree to which the result of adoption can be observed. Complexity relates to the perceived complexity of the functionality. The greater the perceived relative advantage, compatibility, trialability and observability, and, the less complex that the innovation is perceived to be, the more likely it is to be adopted.

Table 2: Cumulative frequency of use of online functionalities on a monthly (daily + weekly + monthly) basis

\begin{tabular}{|c|c|c|c|}
\hline \multirow[b]{2}{*}{ Use of online functionalities } & \multicolumn{3}{|c|}{ Monthly } \\
\hline & $\begin{array}{l}\text { Face to } \\
\text { face }\end{array}$ & $\begin{array}{l}\text { Non face } \\
\text { to face }\end{array}$ & $\begin{array}{c}\text { Differ- } \\
\text { ence }\end{array}$ \\
\hline $\begin{array}{l}\text { Internet/intranet searches for learners to access } \\
\text { information }\end{array}$ & 83.3 & 85.7 & 2.4 \\
\hline Individual email - teacher to learner & 65.2 & 95.2 & 30.0 \\
\hline $\begin{array}{l}\text { Internet/intranet for the distribution of learning } \\
\text { resources as Word, Excel or PowerPoint files }\end{array}$ & 66.2 & 90.5 & 24.3 \\
\hline $\begin{array}{l}\text { Internet/intranet for the distribution of web based } \\
\text { (HTML) learning resources }\end{array}$ & 56.7 & 85.7 & 29.0 \\
\hline $\begin{array}{l}\text { Internet/intranet for the distribution of learning } \\
\text { resources as sound, image or video files }\end{array}$ & 51.5 & 84.2 & 32.7 \\
\hline $\begin{array}{l}\text { Internet/intranet for the distribution of text based } \\
\text { assessment resources, e.g. assignments, case studies }\end{array}$ & 50.0 & 71.4 & 21.4 \\
\hline Group email - teacher to learners & 42.4 & 90.5 & 48.1 \\
\hline Electronic submission of assessment in the form of files & 38.8 & 70.0 & 31.2 \\
\hline Discussion forum(s) & 32.8 & 71.4 & 38.6 \\
\hline $\begin{array}{l}\text { Internet/intranet for computer marked assessment, e.g. } \\
\text { multiple choice, true/false questions }\end{array}$ & 35.4 & 47.6 & 12.2 \\
\hline Bulletin board or notice board(s) & 27.7 & 57.1 & 29.4 \\
\hline ANTA Toolbox products & 19.7 & 57.1 & 37.4 \\
\hline Text chat & 16.4 & 52.4 & 36.0 \\
\hline Virtual classroom software, e.g. Elluminate, Horizon Live & 12.3 & 61.9 & 49.6 \\
\hline Audio conference & 15.2 & 55.0 & 39.8 \\
\hline Group email - learners to learners & 16.7 & 47.6 & 30.9 \\
\hline Blogs (Weblog) & 19.7 & 35.0 & 15.3 \\
\hline E-journal & 16.7 & 36.8 & 20.1 \\
\hline $\begin{array}{l}\text { Internet/intranet based simulations and scenario based } \\
\text { activities including WebQuests }\end{array}$ & 19.7 & 25.0 & 5.3 \\
\hline E-portfolio & 9.1 & 35.0 & 25.9 \\
\hline Video conference & 0.0 & 0.0 & 0.0 \\
\hline Overall average & 33.12 & 59.77 & 26.65 \\
\hline
\end{tabular}


In a more specific consideration of the adoption of information technology, Davis (1989) found that both perceived usefulness and perceived ease of use were significantly correlated with both self reported current and predicted future use. He proposed that perceived ease of use may be a causal antecedent to perceived usefulness.

Davis's (1989) idea of perceived usefulness is consistent with Rogers' (1995) criteria of relative advantage and compatibility. That is, a technology is more likely to be perceived as useful if the practitioner perceives a relative advantage over existing practice and if the technology is compatible with that practice. Davis's (1989) idea of ease of use is consistent with Rogers' (1995) idea of complexity. That is, a technology is more likely to be perceived as easy to use if it lacks complexity. Common to the views of both Rogers (1995) and Davis (1989) is the notion that the adoption of technology is influenced by the individual's perception of the technology. That is, the technology is more likely to be adopted if it is perceived in a positive light. Whilst logical reasoning may influence the person's perception, it may not be adequate to convince the individual that there is a perceived benefit.

Based on previous literature and the results of a survey of deans of education in the USA, Surry, Ensminger and Haab (2005) developed a model for the integration of instructional technology into higher education. Using the acronym RIPPLES, the model includes the seven components of resources, infrastructure, people, policies, learning, evaluation and support (Surry, Ensminger \& Haab, 2005). The authors claimed that whilst this model was developed for colleges of education, it has applicability to other settings. The model proposes that the availability of infrastructure "is the single most important factor in integrating technology into the curriculum" (Surry, Ensminger \& Haab, 2005, p.328).

Resources is concerned with the fiscal resources that support the hardware, software, facilities and network infrastructure capabilities. The people criterion relates to "the needs, hopes, values, skills and experiences of the people who will use the innovation" (Surry, Ensminger \& Haab, 2005, p.328). Policies refers to the need for organisational policies and procedures to support the innovation. Learning refers to the need for administrators to view technology as a means to enhance educational goals. The technology should have pedagogic, access and cost benefits. Evaluation refers to the need to continually assess the benefit of the technology and support refers to the need for training, technical support, pedagogical support and administrative leadership. This model has been used to evaluate the implementation of a learning management system at an Australian university (Benson \& Palaskas, 2006). 
Robertson (2006b) proposed that the criteria of newness, complexity, compatibility and locus of control promote and limit the likelihood that teachers will adopt and use online functionalities. By comparing the likelihood that non-face to face and face to face teachers will use these online functionalities at least monthly, the current paper tests and refines this proposition.

\section{Newness and likelihood of regular use}

Newness relates to the passage of time from the promotion of a functionality for use in education rather than the passage of time from general availability. Newness may be associated with the use of recently developed technology, the use of an existing technology for a new purpose, or within a new context. For example, the use of personal email for private communication may be perceived as different when compared with the use of email to support teaching practice. In a temporal sense, some of the surveyed functionalities have been generally available to support teaching and learning for some years, and others have been introduced more recently. Whilst Rogers (1995) identifies the perception of newness as a characteristic inherent in an innovation, newness is not a criteria explicitly identified by either Rogers (1995) or Davis (1989) in shaping the adoption of that innovation.

Using Robertson's (2006b) data it is reasonable to conclude that, as a general trend, the longer that an online functionality has been available for use in vocational teaching, the greater the likelihood that the functionality will be used at least monthly by vocational teachers irrespective of primary delivery approach. The 13 online functionalities that are most likely to be used by vocational teachers have all been available for some time. These relate to Internet/intranet searches, individual and group email (teacher to learners), the distribution of a range of file types including ANTA Toolbox products (a collection of online resources developed by the Australian Government), electronic submission of assessment, computer marked assessment, discussion forum, bulletin board and text chat. More recently introduced functionalities such as audio conference, virtual classroom software, blogs, ejournals and e-portfolios are less likely to be used regularly.

This finding may not be surprising. What is more interesting is that there is variation in the likelihood of regular use of online functionalities that have been available for some time. Put simply, an increase in the likelihood of regular use is not universal or equal in all cases. Also there are differences between these patterns in the cases of non-face to face and face to face groups.

For example, Internet/intranet based searches are used by more than $80 \%$ of both face to face and non-face to face teachers, individual email (teacher to 
learner) is used by more than $66 \%$ of face to face teachers and more than $90 \%$ of non-face to face teachers on at least a monthly basis. Alternatively, group email (learner to learner), text chat and ANTA Toolbox products are used by less than $20 \%$ of face to face and less than $60 \%$ of non-face to face teachers. All of these functionalities have been available for use in education for some years. These findings beg the questions: What factors influence increase in the use of online functionalities with the passage of time? What factors influence the disparity of use between face to face and non-face to face teachers? These questions are discussed through the following analysis of the criteria of complexity and compatibility.

\section{Complexity, compatibility and likelihood of regular use}

Complexity is related to the difficulty that a vocational teacher is likely to experience in using the functionality. This criterion is consistent with the notions of complexity described by Rogers (1995) and ease of use as described by Davis (1989). The notion of complexity is not inconsistent with the ideas of trialability and observability described by Rogers (1996). That is, less complex technologies are able to be more easily trialed by teachers compared with more complex functionalities.

What vocational teachers may perceive as complex online functionalities is dependent on the teacher's level of technical expertise, the nature of the specific functionality and the specific manner in which it is operationalised. Here, functionalities that are described as complex are characterised as those where a vocational teacher requires assistance from others to use the functionality. Given the descriptors used for some of the online functionalities reported here, interpretation of the notion of complexity is not without problem. For example:

- The use of the Internet/intranet for the distribution of web based (HTML) learning resources may be interpreted as requiring HTML programming skills. This skill may be beyond the capability of the survey respondents who rated their level of technical skill as intermediate. However, for the purposes of the current paper, the findings associated with this functionality are interpreted in a literal sense and restrict the discussion to the distribution of such files.

- Video conferencing may be interpreted as relatively simple personal computer based video functionality such as that available through software including Microsoft Messenger or Skype. It might also be interpreted as video conferencing that requires specialised conferencing facilities using satellite or other transmission technologies.

- Computer marked assessment has been available as an online functionality for some years. In the case of centrally managed and secure computer marked assessment, teachers are likely to require technical 
assistance to establish random access to test questions and testbank security. Alternatively, teachers are likely to be able to develop and distribute simpler forms of computer marked assessment that do not require security codes.

Despite this complication, the data suggests that if an online functionality lacks complexity, as defined by the ability of the practitioner to use the online functionality independently, it is more likely to be used by vocational teachers on a regular basis. For the face to face group, the eight most used online functionalities require the skills of email communication, Internet searching, and use of the Internet/intranet for the distribution or receipt of a range of file types. The same skills are required for the nine most used online functionalities in the case of the non-face to face group. However, this trend is not entirely consistent across the functionalities surveyed. For example, in the case of the non-face to face group, virtual classroom software is more likely to be used regularly than simpler functionalities such as text chat and bulletin boards.

This paper posits that a third factor, compatibility, is critical in shaping this outcome. That is, the more compatible the use of an online functionality is with a teacher's practices and needs, the more likely it is to be adopted and used frequently, a proposition consistent with the work of others (Davis, 1989; Errington, 2001, 2004; Rogers, 1995).

Whilst acknowledging that attempting to assess what vocational teachers might consider as compatible with existing practices and needs is not without issue, this paper undertakes an analysis based on the author's interpretation of the skills and attitudes of a typical vocational teacher.

The teaching practices of face to face and non-face to face vocational practitioners are fundamentally different in respect to the spatial proximity of the teacher and learners. It has already been observed that non-face to face teachers are more likely to use online functionalities than face to face teachers. It is reasonable to suggest that this finding is associated with the general need for non-face to face teachers to find means to enable the distribution of learning resources, communication and relationship building between teachers and learners other than by face to face interaction. Online functionalities provide opportunities to achieve these aims. That is, given the lack of spatial proximity between teachers and learners in non-face to face teaching there is a greater general level of compatibility between online technology and existing practices and needs of non-face to face teachers than face to face teachers.

Virtual classroom software has only been promoted for general use in vocational education for a few years and may require the intervention of 
technical staff to overcome access issues related to firewalls. If relationships between the likelihood of regular use of an online functionality, newness and complexity were universal then one would expect that virtual classroom software would be less likely to be used frequently compared with more established and simpler functionalities. The data provided by Robertson (2006b) shows that this is the case for face to face teachers. For this group virtual classroom software is the third least online functionality to be used monthly, only e-portfolio and video conference are used less by this group. However, in the case of the non-face to face group, virtual classroom software is reported as the tenth most frequently used functionality. Virtual classroom software is more likely to be used frequently than more established and simpler functionalities such as bulletin board, audio conference and text chat by the non-face to face group. It is proposed that given the lack of spatial proximity, and the associated need to find methods to communicate, the use of virtual classroom software is highly compatible with the existing practices and needs of non-face to face teachers. And, that this accounts for the higher than expected likelihood of frequent use when only newness and complexity are considered.

That is, generally, online functionalities are more likely to be used frequently by vocational teachers if they are perceived as established and lacking complexity. This is not however a predictive relationship. Where there is a compatibility with existing practices and perceived need, practitioners are prepared to use a relatively new and possibly more complex technology in favor of established and less complex technologies that are not considered to provide a relative advantage (Rogers, 1995).

\section{Locus of control and likelihood of frequent use}

Locus of control is a fourth criterion that Robertson (2006b) proposed as shaping the frequency with which vocational practitioners will use online functionalities. This criterion is derived from the concept of framing introduced by Basil Bernstein to describe control over the selection of content, communication, sequence, pace and assessment criteria (Bernstein, 1996, 2000). Locus of control shifts the focus of our discussion from criteria associated with the practitioners' perceptions of their relationship with the technology, to a concern for the pedagogic relations between the teacher and learner. It is not a criterion explicitly identified by Rogers (1995) or Davis (1989).

Newness, complexity and compatibility, as used in this paper, are primarily associated with the practitioner's perception of the technology. That is, they address the questions: is the technology new to me; am I able to use the technology without the assistance of others; and, is the technology compatible with the way that I practise and my needs? Whereas 
compatibility is concerned with the congruence between the technology, existing practice and perceived needs, locus of control is explicitly concerned with the pedagogic relation between the teacher and learners. Whilst it is reasonable to argue that pedagogic concerns are embedded in teachers' existing practices, locus of control makes the pedagogic preferences of teachers explicit. This section of the paper examines the proposition that the greater the potential of an online functionality to situate the control of pedagogic decisions with the teacher, the more likely the technology is to be used regularly.

That teaching practice in VET should move from teacher centred to learner centred has been promoted by academics, vocational teachers and in policy. Banners such as 'from sage on the stage to guide on the side' (King, 1993) have been popularised. Constructivist learning principles which are consistent with learner centredness have been promoted generally in VET and have been reflected in principles of 'good design' using online technology (Australian National Training Authority, 2004; Boud \& Prosser, 2002; Brennan, McFadden, \& Law, 2001; Gooding, 2002; Oliver, 2001; Oliver et al., 2001).

Whilst acknowledging that the level of teacher or learner control that is experienced is dependent on how an online functionality is operationalised, it is possible to classify the potential to shift the locus of control from the teacher to the learner. For example, the distribution of 'content rich' learning materials in a range of file formats (e.g. text, audio, visual), and text based assessment is more likely to result in teacher controlled pedagogy. The use of communication functionalities such as individual and group email (teacher to learners) and bulletin board or notice board(s) place the teacher at the centre. Computer marked assessment is designed and controlled by the teacher.

These online functionalities with a teacher centred bias have generally been available for some time but vary in complexity. They account for eight of the top eleven functionalities used by both face to face and non-face to face groups. Other functionalities represented in the eleven most likely to be used functionalities are the electronic submission of assessment, discussion forums, and Internet/intranet searches to access information. All three are established online functionalities that lack complexity. Electronic submission of assessment does not shift locus of control from teacher to learner. Discussion forums and Internet/intranet to search for information have potential to shift the locus of control towards the learner. However, in practice, these functionalities are also established and moderated by teachers. 
Online functionalities that have a greater potential to shift the control from the teacher to learners include functionalities for the distribution of 'content light' resources that require learners to actively engage in developing knowledge and understanding. Examples include simulations and scenario based activities; learner controlled communication such as individual and group email between learners; and, functionalities that promote learner opportunities to reflect on knowledge and understandings such as blogs, ejournals and e-portfolios.

E-journals, e-portfolios and blogs have the potential to move the locus of control from the teacher to the learner. Whilst teachers may provide direction on the requirements of an e-journal, e-portfolio or blog and may be responsible for monitoring and assessing these learning strategies, the learner has more potential control over the design and development of these artifacts than is the case for predetermined content. Robertson (2006b) found that, with the exception of video conferencing which is reported as a zero use on a monthly basis, these 'learner centred' functionalities are the least used by both face to face and non-face to face groups. All are relatively new online functionalities, which to some degree accounts for the low likelihood that vocational practitioners will use these at least monthly. It will be interesting to observe the trends in use of these relatively simple and recent introductions to VET over time.

Other online functionalities that have the potential to shift the locus of control from teacher to learner are learner-learner email and simulations. For both, data on at least monthly use support the conclusion that online functionalities which bias the locus of control towards the learner are less likely to be used frequently by vocational teachers than those functionalities that are biased towards teacher control.

The use of email is an example of an online functionality that is established and relatively simple to use. Individual email (teacher-learner) is the most frequently used online functionality by non-face to face teachers and third most frequently used by face to face teachers. Group email (teacher to learners) is the second most frequently used online functionality by non-face to face teachers and seventh most used online functionality by face to face teachers. These data suggest that vocational teachers have the technical skills to use email with independence. At least monthly use of group email for learner to learner communication is the 15th/16th most used functionality. This finding is not inconsistent with the proposition that online functionalities that are biased towards learner centredness are less likely to be used than uses that are more teacher centred.

ANTA Toolbox products and Internet/intranet based simulations and scenarios have been promoted for use in vocational education for some years 
but are generally perceived as relatively complex by many teachers. Both provide a potential learning opportunity that is more exploratory than expository. Like group email (learner to learner) they provide an example where the functionality has the potential to shift the locus of control from teacher to learners. ANTA Toolbox products are the 12th most frequently used online functionality for face to face and eleventh most frequently used for the non-face to face groups. Internet/intranet based simulations and scenarios are equal 12th most frequently used for the face to face group and 20th most likely for the non-face to face group.

The likelihood that group email (learner-learner), ANTA Toolbox products and Internet/intranet based simulations and scenarios will be used at least monthly is greater for the non-face to face than face to face teacher groups. Is it possible to propose that the relatively higher level of monthly use by nonface to face teachers is driven by the need to provide learners with resources to support their learning in the absence of spatial proximity? That is, in cases where there is a higher level of compatibility between the online functionality and existing practices and needs, practitioners are more likely to use learner centred online functionalities more frequently.

\section{Discussion}

The above analysis supports the proposition that the criteria of newness, complexity, compatibility and locus of control are associated with shaping the likelihood that vocational teachers will use online functionalities at least monthly. Newness, complexity and compatibility are described as a relationship between the teacher and the technology. Locus of control is described as focusing on the likely impact of online functionalities on the pedagogic relationship between the teacher and learners.

Although not universal or equal in all cases, it is found that the longer an online functionality has been available for use in vocational education, the greater the likelihood that the functionality will be used regularly by face to face and non-face to face vocational teachers. In addition, teachers are more likely to use an online functionality frequently if it lacks complexity. That is, teachers are able to use the online functionality without the assistance of a third party.

Alone and in combination, the influence of the two factors of newness and complexity may not be unexpected. However, the relationship between newness, complexity and frequency of use is not a simple one. For example, data analysis in this paper shows that despite being relatively new and possibly complex, virtual classroom software is used at least monthly by almost two-thirds of non-face to face teachers. Here, newness and complexity do not prohibit the regular use of a functionality. In this case, it is 
proposed that practitioners are prepared to use a relatively new and more complex functionality if it is compatible with the existing practices and needs.

If online functionalities are more likely to be implemented when their design and use is consistent with the perceived needs of users, then change strategies consistent with adopter based approaches are likely to be more successful than top down approaches. The adopter based approach consults potential users with the intention of designing and developing a user friendly product. The potential adopter is informed about the product's user friendliness and post-adoption support is provided (Surry, 1997). The use of this approach to the implementation of online technology in Australia has been reported (Hansen \& Salter, 2001). Taking an adopter based approach is consistent with acknowledging that the adoption of technology must consider more than the technical superiority of an innovation, if it is to be adopted. The adoption of an innovation must not 'underestimate the impact of teacher beliefs on any proposed changes' (Errington, 2001, p.36).

The notion of compatibility, as described in the current paper, is consistent with the criterion of 'people' as described in Surry et al's (2005) RIPPLES model. Both recognise the importance of practitioner's needs and perceptions. This is consistent with the work of others who identify the importance of values, beliefs, dispositions and teacher's practical theories in shaping the practices that they adopt and the need to address these issues in professional development (Errington, 2004; Marland, 1998; Robertson, 2006c).

Whilst it is not possible for implementing authorities to control the emergence of online functionalities, it is reasonable to suggest that approaches which increase practitioner awareness of online functionalities and their potential application to education may be useful in increasing adoption. Teachers' general levels of technical capability will influence the range of online functionalities that they can use independently, and the likelihood that online functionalities will be used frequently in their practice. To increase teacher confidence with online technology, professional development that provides practitioners with an awareness of the functionality's potential and the specific technical, as well as pedagogic skills, to use the functionality may assist. These suggestions are consistent with Surry et al (2005) who identify: the availability of hardware, software and networks; and, formal and informal training, technical and pedagogic support as elements that need to be addressed in integrating online technology into higher education.

Whereas compatibility is described as a concept that incorporates teacher's existing practices and needs, locus of control is more specifically concerned 
with teacher's pedagogic preferences. Here, locus of control is consistent with Basil Bernstein's concept of framing which is concerned with control over the selection of communication, sequencing, pacing, and criteria for assessment (Bernstein, 1996, 2000). The current paper presents evidence to suggest that online functionalities which have a bias towards teacher centredness are more likely to be used at least monthly compared with those having a bias to learner centredness. This conclusion must be tempered with the observation that established online functionalities, such as the Internet for the distribution of resources, are more likely to have a tendency to support teacher centred approaches. Alternatively, the emergence of online functionalities such as blogs and e-portfolios that have a greater tendency to support learner centredness is a relatively recent phenomenon. Given that established functionalities are more likely to be used frequently than newer functionalities, whether the trend towards more frequent use of teacher centred functionalities will continue over time is yet to be established. This caution accepted, the constructivist approach characterised by learner centredness has been promoted when implementing online technologies into VET (Australian National Training Authority, 2004; Brennan, 2003; Oliver, 2001). As a consequence the proposition that VET teachers are likely to use online functionalities that preference teacher centredness is somewhat problematic and requires further investigation. To commence this discussion a brief consideration of institutional, teacher preferences and learner preferences is provided.

At an institutional level, competency based training (CBT) is central to the design, delivery and assessment of teaching and learning in VET. CBT finds its roots in the behaviourist perspective which emphasises 'identification, observation and measurement of human behaviour' (Billett et al., 1999, p.17). Whilst the VET system has promoted flexible learning, which is characterised by a greater level of learner control in respect to sequence and pace, these become subservient to teacher control over content and assessment which are preferenced by CBT.

Practitioners' preferred pedagogic approaches as well as learner preferences also influence the bias towards teacher or learner centred approaches. The role of values and beliefs in influencing teachers' practices has already been identified and is not discussed further at this time. However, in trying to accommodate the learning preferences of students, teachers are likely to adapt teaching practices to meet the needs of learners. Evidence suggests that VET students are inclined towards learning that is teacher directed (Choy \& Delahaye, 2000; Pratt \& Collins, 2000; Smith, 2000a, 2000b). If this is the case, then teachers may adopt a teacher centred approach in order to accommodate the preferred styles of learners. 


\section{Conclusion}

Using empirical evidence this paper draws some conclusions that would seem to be self evident and identifies trends in the frequency of use of online functionalities that require further investigation.

That the frequency of use of online functionalities is variable, that more established and simple online functionalities are more likely to be used frequently, and that non-face to face teachers are more likely to use online functionalities more frequently than face to face teachers, would seem to be intuitively obvious. More interesting is the apparently complex relationship between the criteria of newness, complexity, compatibility and locus of control that has been proposed. It has been shown that teachers are prepared to use newer and more complex online functionalities that are potentially more learner centred. It is proposed that this situation occurs where the level of compatibility with existing practices and perceived needs outweighs the factors of newness and complexity.

The notion of compatibility is discussed in terms of teacher's values, beliefs and personal theories, and implications are briefly explored. The need for further research into the observation that teachers are more likely to use online functionalities that preference teacher centredness is identified.

\section{References}

Australian National Training Authority (2000). Flexible learning for the information economy. A framework for national collaboration in vocational education and training 2000-2004. Brisbane: Australian National Training Authority.

Australian National Training Authority (2004). Developing quality online materials. The flexible learning Toolbox experience. Melbourne: Australian National Training Authority. \{verified 21 Jul 2007; 4.47 MB] http: / / toolboxes.flexiblelearning. net.au/documents/docs/Toolbox_Experience_Report_Final.doc

Benson, R. \& Palaskas, T. (2006). Introducing a new learning management system: An institutional case study. Australasian Journal of Educational Technology, 22(4), 548567. http: / / www.ascilite.org.au/ajet/ajet22/benson.html

Bernstein, B. (1996). Pedagogy, symbolic control and identity. Theory, research, critique. London: Taylor and Francis.

Bernstein, B. (2000). Pedagogy, symbolic control and identity: Theory, research, critique (Rev. ed.). Lanham, Maryland: Rowman \& Littlefield.

Billett, S., McKavanagh, C., Beven, F., Angus, L., Seddon, T., Gough, J., Hayes, S. \& Robertson, I. (1999). The CBT decade. Teaching for flexibility and adaptability. Leabrook: National Centre for Vocational Education Research. [Exec summary verified 21 Jul 2007] http:/ / www.ncver.edu.au/research/proj/nr7029e.htm 
Boud, D. \& Prosser, M. (2002). Appraising new technologies for learning: A framework for development. Educational Media International, 39(3/4), 237-245. [verified 21 Jul 2007] http:/ / www.education.uts.edu.au/ostaff/staff/ publications / DB37Boud_ProsserEMI02.pdf

Brennan, R. (2003). One size doesn't fit all. The pedagogy of online delivery in Australia. In H. Guthrie (Ed), Online learning. Research findings (pp. 55-70). Leabrook: National Centre for Vocational Education Research Ltd.

Brennan, R., McFadden, M., \& Law, E. (2001). Review of research. All that glitters is not gold: Online delivery of education and training. Leabrook: National Centre for Vocational Education Research.

Choy, S. \& Delahaye, B. (2000). Learning approaches, study orientation and readiness for self-directed learning of youth in TAFE. Paper presented at the Vocational Education and Training Research Conference, Coffs Harbour, 4-7 July. [verified 21 Jul 2007] http: / / www.voced.edu.au/docs/confs/ncver/vetconf9/tr9choydel.rtf

Davis, F. (1989). Perceived usefulness, perceived ease of use, and user acceptance of information technology. MIS Quarterley, 13, 319-340.

Department of Education, Science and Training (2005). 2006 Framework Business Plan. Australian Flexible Learning Framework for the national vocational and technical education system. Canberra: Department of Education, Science and Training. [verified 21 Jul 2007] http: / / pre2005.flexiblelearning.net.au/aboutus/2006\%20 Framework $\%$ 20Business $\% 20$ Plan_final_accepted $\% 20$ changes.doc

Errington, E. (2001). The influence of teacher beliefs on flexible learning innovation in traditional university settings. In F. Lockwood \& A. Gooley (Eds.), Innovation in open and distance learning. Successful development of online and web-based learning (pp. 27-37). London: Kogan Page.

Errington, E. (2004). The impact of teacher beliefs on flexible learning innovation: Some practices and possibilities for academic developers. Innovations in Education and Teaching International, 41(1), 39-47.

Gooding, K. (2002). Problem based learning online. In Untangling the Web: Establishing Learning Links. Proceedings ASET Conference 2002, Melbourne, 7-10 July. http: / / www.ascilite.org.au/ aset-archives/confs / 2002/gooding.html

Hansen, S. \& Salter, G. (2001). The adoption and diffusion of web technologies into mainstream teaching. Journal of Interactive Learning Research, 12(2/3), 281-299.

I \& J Management Services (2005). 2005 E-learning benchmarking project - Final report. Canberra: Department of Education, Science and Training. [verified 21 Jul 2007] http: / / e-learningindicators.flexiblelearning.net.au/pdf/elearningbenchmarking Final_report.pdf

I \& J Management Services. (2006). 2006 E-learning benchmarking project. Department of Education, Science and Training. [verified 21 Jul 2007] http:/ / e-learningindicators .flexiblelearning.net.au/pdf/benchmarking_report2006.pdf

King, A. (1993). From sage on the stage to guide on the side. College Teaching, 41(1), 3035.

Marland, P. (1998). Teachers' practical theories: Implications for preservice teacher education. Asia-Pacific Journal of Teacher Education E Development, 1(2), 15-23. 
NCVER. (2004). Profiling the national vocational education and training workforce. Adelaide: National Centre for Vocational Education Research.

Oliver, R. (2001). Seeking best practice in online learning: Flexible Learning Toolboxes in the Australian VET sector. Australian Journal of Educational Technology, 17(2), 204-222. http:/ / www.ascilite.org.au/ajet/ajet17/oliver.html

Oliver, R., Towers, S., Skippington, P., Brunetto, Y., Farr-Wharton, R. \& Gooley, A. (2001). Flexible toolboxes: A solution for developing online resources? In F. Lockwood \& A. Gooley (Eds), Innovation in open and distance learning. Successful development of online and web-based learning (pp. 100-110). London: Kogan Page.

Pratt, D. \& Collins, J. (2000). The Teaching Perspectives Inventory (TPI). Paper presented at the Adult Education Research Conference, University of British Columbia. [verified 21 Jul 2007] http:/ / www.edst.educ.ubc.ca/faculty/pratt/DPaerc.html

Robertson, I. (2006a). Deconstruction, confusion and frequency: Surveying technology use by vocational teachers. Paper presented at the 9th Annual AVETRA Conference. Global VET: Challenges at the Global, National and Local Levels, University of Wollongong, 19-21 April. [verified 21 Jul 2007]

http: / / www.avetra.org.au/publications / documents/PA\%200031.pdf

Robertson, I. (2006b). Surveying online technology: A matter of design. The Knowledge Tree, May, 38-49. [verified 21 Jul 2007] http:/ / kt.flexiblelearning.net.au/wpcontent/uploads/2006/05/robertson.pdf

Robertson, I. (2006c). Teachers integrating online technology in TAFE. Unpublished Doctor of Education thesis, Monash University, Melbourne. [verified 21 Jul 2007] http: / / robboian.googlepages.com/ doctorofeducationthesis

Rogers, E. (1995). Diffusion of innovations (4th ed.). New York: The Free Press.

Smith, P. (2000a). Flexible delivery and apprentice training: Preferences, problems and challenges. Journal of Vocational Education and Training, 52(3), 483-502.

Smith, P. (2000b). Preparedness for flexible learning among vocational learners. Distance Education, 21(1), 29-48.

Surry, D. (1997). Diffusion theory and instructional technology. Annual Conference of the Association for Educational Communications and Technology (AECT), 11-15 February. [viewed 4 Jun 2007] http:/ / www2.gsu.edu/ wwwitr/docs/diffusion/

Surry, D., Ensminger, D. \& Haab, M. (2005). A model for integrating technology into higher education. British Journal of Educational Technology, 36(2), 327-329.

Surry, D., Ensminger, D. \& Jones, M. (2003). A model for integrating instructional technology into higher education (Publication. [viewed 7 Jun 2007] http:/ / iphase.org/papers/RIPPLES.rtf

Dr Ian Robertson, Senior Lecturer, School of Education, RMIT University, Swanston Street, Melbourne Vic 3000, Australia.

Email: ian.robertson@rmit.edu.au 